\title{
Lercanidipine Effect on Polymorphonuclear Leukocyte-Related Inflammation and Insulin Resistance in Essential Hypertension Patients
}

\author{
Raymond Farah $\cdot$ Revital Shurtz-Swirski $\cdot$ Rola Khamisy-Farah
}

To view enhanced content go to www.cardiologytherapy-open.com

Received: June 11, 2012 / Published online: October 9, 2012

(C) The Author(s) 2012. This article is published with open access at Springerlink.com

\section{ABSTRACT}

Introduction: Inflammation, insulin resistance, and oxidative stress (OS) are among the mechanisms that have been implicated in the pathogenesis of essential hypertension (EH). Peripheral polymorphonuclear leukocytes (PMNLs) are primed in $\mathrm{EH}$ patients, releasing uncontrolled superoxide anions contributing to OS in these patients. PMNL priming correlates with insulin resistance and PMNL intracellular calcium $\left(\left[\mathrm{Ca}^{2+}\right]_{\mathrm{i}}\right)$. Recent studies have attributed additional anti-ischemic and antioxidative characteristics to the antihypertensive drug,

R. Farah $(\square)$

Department of Internal Medicine B, Ziv Medical

Center, Safed, Israel

e-mail: Raymond.F@ziv.health.gov.il

R. Farah · R. Shurtz-Swirski

Faculty of Medicine in the Galilee, Bar-Ilan

University, Safed, Israel

R. Khamisy-Farah

Clalit Health Service, Western Galilee, Israel

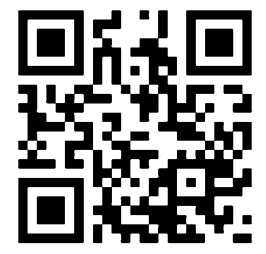

Enhanced content for this article is

available on the journal web site:

www.cardiologytherapy-open.com lercanidipine, a third-generation calciumchannel blocker. The purpose of this study was to evaluate the possible nontraditional effect of 2 months of lercanidipine treatment on insulin resistance and on PMNL-related inflammation in $\mathrm{EH}$ patients.

Methods: Non-smoking EH patients with untreated mild-to-moderate high blood pressure (BP) were included. Low-grade inflammation was reflected by PMNL apoptosis and by white blood cell (WBC) and PMNL counts. Systemic inflammation was measured by plasma fibrinogen, C-reactive protein (CRP), and transferrin and albumin levels. Fasting serum insulin levels served as a marker of insulin resistance.

Results: Two months of lercanidipine treatment showed a significant decrease in BP, WBC, and PMNL counts, PMNL apoptosis, CRP, and serum insulin levels, and a significant increase in serum albumin levels. Rates of superoxide release from PMNLs, WBC and PMNL counts, and insulin levels positively correlated with mean arterial BP values.

Conclusion: The use of lercanidipine can be favorable in $\mathrm{EH}$ patients due to its combined anti-PMNL priming and anti-inflammatory 
effects, in addition to its antihypertensive characteristics.

Keywords: Cardiology; Essential hypertension; Insulin resistance; Lercanidipine; Low-grade inflammation; Oxidative stress; Primed polymorphonuclear leukocytes

\section{INTRODUCTION}

Essential hypertension (EH) is a substantial public health problem, affecting $25 \%$ of the adult population in industrialized societies [1]. This multifactorial and multigenetic disorder is a major risk factor for many common causes of mortality and morbidity including stroke, myocardial infarction, congestive heart failure, and end-stage renal disease [2]. Insulin resistance is seen in more than half of patients with $\mathrm{EH}$ [3]. Despite the important role of $\mathrm{EH}$ as a cause of disease, its pathogenesis remains largely unknown.

Abnormalities in endothelial function and morphology appear to play a central role in the pathogenesis of hypertension-related atherosclerosis [4]. Among the mechanisms causing endothelial dysfunction that have been recently implicated in $\mathrm{EH}$ is oxidative stress (OS), which may impair endotheliumdependent vasodilatation, inflammation, and insulin resistance [5]. Primed peripheral polymorphonuclear leukocytes (PMNLs) are one of the main types of inflammatory cells; once activated, primed PMNLs release reactive oxygen species (ROS), contributing to OS, lowgrade inflammation, endothelial damage, and atherosclerosis in the long term [6, 7]. Recently, the authors have previously reported that PMNLs contribute to the OS and inflammation in correlation with insulin resistance and PMNL intracellular calcium $\left(\left[\mathrm{Ca}^{2+}\right]_{\mathrm{i}}\right)$ in $\mathrm{EH}[8,9]$. In addition, the authors have recently implicated
PMNL priming as a key mediator of low-grade inflammation and OS associated with renal failure [10]; thus, constituting a common denominator in clinical states, such as hypertension, renal failure, and diabetes, and in cigarette smoking, which is known to be associated with endothelial dysfunction and accelerated atherosclerosis [8-12].

The long-acting calcium channel blockers (CCB), widely used in the clinical setting, have been shown to prevent atherosclerosis [13-15], among which amlodipine has an antioxidative action in vivo [16]. In the current study, the authors examined the effects of monotherapy using lercanidipine, a vasoselective dihydropyridine CCB that causes systemic vasodilatation by blocking the influx of calcium ions through L-type calcium channels in cell membranes. As a highly lipophilic drug, lercanidipine has a slower onset, longer duration of action, and fewer adverse effects than a number of other CCB [17]. In well-controlled clinical studies, once-daily administration of 10 or $20 \mathrm{mg}$ lercanidipine effectively reduced blood pressure compared with placebo in patients with mild-to-moderate hypertension without affecting heart rate [18]. However, there are no precedent studies that demonstrate the various effects of this drug on systemic and PMNLrelated inflammation, and on insulin resistance over a period of 2 months of treatment. Thus, the objective of the present study was to determine the effect of lercanidipine on these parameters in $\mathrm{EH}$.

\section{MATERIALS AND METHODS}

\section{Patients}

Fifteen untreated EH patients (12 males/3 females) with mild-to-moderate hypertension 
(age range 20-65 years) and 15 age and gendermatched healthy controls (NCs) were enrolled in this prospective study. Inclusion criteria of the EH group were: sitting diastolic blood pressure (DBP) $>90 \mathrm{mmHg}$ (average of three outpatient visits); sitting systolic blood pressure (SBP) $>140 \mathrm{mmHg}$ (average as above); body mass index $<30 \mathrm{~kg} / \mathrm{m}^{2}$; no evidence of target organ damage and systemic diseases supported by microalbumin/creatinine ratio, fundus examination, echocardiogram test, and kidney function tests. Subjects with evidence of acute or chronic infection, inflammation, receiving medication, vitamins, or antioxidants, smoking, and secondary causes of hypertension were excluded. The selection of all participants was based upon a clinical examination and laboratory confirmation. All subjects had normal fasting ( $>14 \mathrm{~h})$, serum cholesterol $(<205 / 230 \mathrm{mg} / \mathrm{dL})$, triglycerides $(<158 \mathrm{mg} / \mathrm{dL})$, and glucose levels with normal kidney and liver function (Table 1). The study was approved by signing an informed consent for blood sampling approved by the institutional committee in accordance with the Declaration of Helsinki.

Blood was drawn in the morning after an overnight fast from all $\mathrm{EH}$ patients and $\mathrm{NC}$ subjects for the determination of biochemical and hematological parameters, and for PMNL

Table 1 The changes in measurements of EH patients

\begin{tabular}{|c|c|c|c|c|c|}
\hline & NC & Untreated EH & 1-month treatment & 2-month treatment & $P$ value \\
\hline Fundus & Negative & Negative & Negative & Negative & \\
\hline SBP $(\mathrm{mmHg})$ & $120 \pm 3.0^{\mathrm{a}}$ & $162 \pm 4.0$ & $146 \pm 3.0^{\mathrm{a}}$ & $143 \pm 3.0^{\mathrm{a}}$ & $<0.01$ \\
\hline $\mathrm{DBP}(\mathrm{mmHg})$ & $69 \pm 2.0^{\mathrm{a}}$ & $100 \pm 1.0$ & $89 \pm 3.0^{\mathrm{a}}$ & $87 \pm 2.0^{\mathrm{a}}$ & $<0.01$ \\
\hline MAP (mmHg) & $86 \pm 2.0^{\mathrm{a}}$ & $120 \pm 2.0$ & $108 \pm 2.0^{\mathrm{a}}$ & $107 \pm 2.0^{\mathrm{a}}$ & $<0.01$ \\
\hline Cholesterol $(\mathrm{mg} / \mathrm{dL})$ & $205 \pm 1.7$ & $230 \pm 9.3$ & $225 \pm 13.2$ & $226 \pm 15.6$ & NS \\
\hline Triglycerides $(\mathrm{mg} / \mathrm{dL})$ & $120 \pm 3.2$ & $158 \pm 26.0$ & $149 \pm 19.2$ & $130 \pm 23.7$ & NS \\
\hline $\mathrm{HDL}(\mathrm{mg} / \mathrm{dL})$ & $58 \pm 0.7$ & $42.8 \pm 1.4$ & $40.4 \pm 2.0$ & $39.2 \pm 3.3$ & NS \\
\hline $\mathrm{LDL}(\mathrm{mg} / \mathrm{dL})$ & $114 \pm 1.3$ & $155 \pm 6.6$ & $155 \pm 10.8$ & $161 \pm 11.8$ & NS \\
\hline Glucose $(\mathrm{mg} / \mathrm{dL})$ & $94 \pm 1.9$ & $89.1 \pm 4.5$ & $98.4 \pm 3.4$ & $100.8 \pm 5.0$ & NS \\
\hline Creatinine $(\mathrm{mg} / \mathrm{dL})$ & $0.93 \pm 0.02$ & $0.96 \pm 0.03$ & $0.98 \pm 0.04$ & $0.95 \pm 0.04$ & NS \\
\hline $\operatorname{ALT}(\mathrm{U} / \mathrm{L})$ & $20 \pm 0.5$ & $38.0 \pm 6.2$ & $30.7 \pm 6.3$ & $38.4 \pm 5.0$ & NS \\
\hline AST $(\mathrm{U} / \mathrm{L})$ & $19.6 \pm 0.3$ & $26.6 \pm 3.3$ & $25.4 \pm 5.1$ & $24.0 \pm 3.6$ & NS \\
\hline $\operatorname{ALP}(\mathrm{U} / \mathrm{L})$ & $75 \pm 6.1$ & $87.8 \pm 5.5$ & $83.7 \pm 5.4$ & $81.9 \pm 5.0$ & NS \\
\hline LDH (U/L) & $283 \pm 1.9$ & $294 \pm 11.9$ & $311 \pm 17.0$ & $313 \pm 13.0$ & NS \\
\hline $\mathrm{Hb}(\mathrm{g} / \mathrm{dL})$ & $14.3 \pm 0.1$ & $14.7 \pm 0.3$ & $14.6 \pm 0.3$ & $14.7 \pm 0.2$ & NS \\
\hline Insulin $(\mathrm{U} / \mathrm{mL})$ & $8.4 \pm 0.9^{\mathrm{a}}$ & $15.1 \pm 1.1$ & $16.4 \pm 4.1$ & $10.1 \pm 1.1^{\mathrm{a}}$ & $<0.01$ \\
\hline
\end{tabular}

Values are mean \pm SEM

$A L P$ alkaline phosphatase, $A L T$ alanine transaminase, $A S T$ aspartate aminotransferase, $D B P$ diastolic blood pressure, $E H$ essential hypertension, $H b$ hemoglobin, $H D L$ high-density lipoprotein, $L D H$ lactate dehydrogenase, $L D L$ low-density lipoprotein, $M A P$ mean arterial pressure, $N C$ normal control, $N S$ not significant, $S B P$ systolic blood pressure

a Versus untreated $\mathrm{EH}$ patients 
isolation. Blood was drawn from $\mathrm{EH}$ patients before and following treatment with $10 \mathrm{mg}$ /day lercanidipine for 1 and 2 months.

PMNL isolation was carried out from a $20-\mathrm{mL}$ heparinized blood sample as previously described [10, 19]. The separated PMNLs ( $>98 \%$ pure, approximately $10^{7}$ cells per isolation) were resuspended in phosphatebuffered saline (PBS) containing 0.1\% glucose. Sera and plasma were frozen at $-20^{\circ} \mathrm{C}$ for determining the clinical and biochemical characteristics of the participants, and for systemic inflammation parameters.

\section{PMNL Priming}

\section{Rate of Superoxide Release}

The measurements of the rate of superoxide release are based on superoxide dismutase (SOD) inhibitable reduction of $80 \mu \mathrm{M}$ cytochrome C (Sigma, St. Louis, MO, USA) to its ferrous form [20]. The rate of superoxide release was monitored from $10^{6}$ separated PMNLs, after stimulation with $0.32 \times 10^{-7} \mathrm{M}$ phorbol 12-myristate 13-acetate (PMA; Sigma, St. Louis, $\mathrm{MO}, \mathrm{USA})$, at $22^{\circ} \mathrm{C}$ for $50 \mathrm{~min}$. This parameter was used as a measure of PMNL priming.

\section{PMNL-Derived Inflammation}

\section{WBC and PMNL Counts}

Counts of WBC and PMNLs from blood drawn in ethylenediaminetetraacetic acid (EDTA) were performed by an automated cell counter (Coulter STKS Analyzer, Coulter Corporation, Miami, FL, USA) and used as a measure of lowgrade inflammation.

\section{Analysis of Apoptotic PMNLs}

Apoptosis was analyzed in whole blood from EH patients and NC subjects of each group by flow cytometry according to Kuypers et al. [21]. Blood samples were assayed for apoptosis after lysis of red blood cells by Q PREP ${ }^{\mathrm{TM}}$ (Beckman Coulter, Inc., Galway, Ireland) and incubated with fluorescein isothiocyanate (FITC)-labeled monoclonal antibodies using the Annexin V kit (Bender MedSystems, Vienna, Austria). PMNLs were defined by forward scatter/side scatter and by R-phycoerythrin (PE)-labeled monoclonal anti-CD16.

\section{Systemic Inflammation}

\section{Measurement of Plasma Fibrinogen}

Fibrinogen was measured in a Cobas Mira plus instrument (Roche, Mannheim, Germany), in all plasma samples using the $\mathrm{K}_{\text {-Assay }}{ }^{\circledR}$ kit (Kamiya Biomedical Company, Seattle, WA, USA).

\section{Measurement of C-Reactive Protein, Transferrin, and Albumin}

C-reactive protein (CRP), transferrin, and albumin were routinely assayed in the biochemistry lab using a Hitachi 917 Automatic Analyzer (Roche Diagnostics, Mannheim, Germany) in separated sera obtained from all $\mathrm{EH}$ patients and NC subjects after an overnight fast.

\section{Insulin as a Marker of Insulin Resistance}

Fasting serum insulin levels served as a measure for insulin resistance, and were measured using an electrochemiluminescence immunoassay kit (Roche Diagnostics, Mannheim, Germany). Insulin resistance was also verified by homeostasis model assessment-insulin resistance (HOMA-IR) test.

\section{Statistical Analysis}

Data are expressed as mean \pm SEM. Differences in mean values were tested by two-way analysis 
of variance (ANOVA) and by the Bonferroni multiple comparison test, using Prism version 3.0 statistical software (GraphPad software, San Diego, CA, USA). Correlations between different study parameters were performed using Pearson correlation coefficients. $P<0.05$ was considered significant.

\section{RESULTS}

\section{Study Population}

Table 1 summarizes the clinical and biochemical characteristics of the participants. All studied groups of patients showed similar serum cholesterol, serum creatinine, serum triglycerides, liver enzymes, and serum glucose levels, without showing target organ damage. Most traditional risk factors were similar during the lercanidipine treatment period. Blood pressure values, namely DBP, SBP, and mean arterial pressure (MAP) decreased significantly following 1 and 2 months of lercanidipine treatment (Table 1).

\section{PMNL Priming}

\section{Rate of Superoxide Release}

Significantly faster rates of superoxide release from PMA-stimulated PMNLs were found in $\mathrm{EH}$ patients before and following 2 months of lercanidipine treatment (Table 2), as compared to NCs $\left(18.2 \pm 1.2 \mathrm{nmol} / 10^{6}\right.$ cells $\left./ 10 \mathrm{~min}\right)$, reflecting a higher priming state in these groups (EH). Two months of treatment reflected a slight, though significant, decrease in the rate of superoxide release from PMAstimulated PMNLs (Table 2).

\section{PMNL-Derived Inflammation}

\section{WBC and PMNL Counts}

EH patients had significantly higher numbers of WBC and PMNLs (Table 2), as compared to NC subjects $\left(7.2 \pm 0.1\right.$ and $3.9 \pm 0.2 \times 10^{9}$ cells $/ \mathrm{mL}$,

Table 2 PMNL-related inflammation and priming and systemic inflammation parameters

\begin{tabular}{lccccc}
\hline & NC & $\begin{array}{l}\text { Untreated } \\
\text { EH }\end{array}$ & $\begin{array}{l}\text { 1-month } \\
\text { treatment }\end{array}$ & $\begin{array}{l}\text { 2-month } \\
\text { treatment }\end{array}$ & P value \\
\hline WBC $\times 10^{9}$ & $7.2 \pm 0.1$ & $7.8 \pm 0.5$ & $7.4 \pm 0.4$ & $7.1 \pm 0.2^{\mathrm{a}}$ & $<0.05$ \\
PMNL $\times 10^{9}$ & $3.9 \pm 0.2^{\mathrm{a}}$ & $4.8 \pm 0.4$ & $4.4 \pm 0.4$ & $4.2 \pm 0.2^{\mathrm{a}}$ & $<0.05$ \\
PMNL apoptosis (\%) & $2.8 \pm 0.7^{\mathrm{a}}$ & $15.4 \pm 1.8$ & $11.5 \pm 2.0$ & $7.2 \pm 1.0^{\mathrm{a}}$ & $<0.05$ \\
Rate of superoxide release $\left(\mathrm{nmol} / 10^{6}\right.$ cells/10 min) & $18.2 \pm 1.2$ & $29.0 \pm 1.6$ & $31.7 \pm 1.3$ & $27.5 \pm 1.3^{\mathrm{b}}$ & $<0.05$ \\
Fibrinogen $(\mathrm{mg} / \mathrm{dL})$ & $289 \pm 12.0^{\mathrm{a}}$ & $393 \pm 48.0$ & $387 \pm 34.0$ & $367 \pm 30.0$ & $\mathrm{NS}$ \\
Albumin $(\mathrm{g} / \mathrm{dL})$ & $4.6 \pm 0.05^{\mathrm{a}}$ & $4.5 \pm 0.06$ & $4.6 \pm 0.07$ & $4.6 \pm 0.05^{\mathrm{a}}$ & $<0.05$ \\
Transferrin $(\mathrm{g} / \mathrm{dL})$ & $273 \pm 5.0^{\mathrm{a}}$ & $288 \pm 8.0$ & $276 \pm 6.0$ & $274 \pm 7.0$ & $\mathrm{NS}$ \\
$\mathrm{CRP}(\mathrm{mg} / \mathrm{L})$ & $1.46 \pm 0.1^{\mathrm{a}}$ & $3.91 \pm 0.9$ & $3.04 \pm 0.9$ & $1.67 \pm 0.6^{\mathrm{a}}$ & $<0.05$ \\
\hline
\end{tabular}

Values are mean \pm SEM

$C R P$ C-reactive protein, $E H$ essential hypertension, $N C$ normal control, $N S$ not significant, $P M N L$ peripheral polymorphonuclear leukocytes, $W B C$ white blood cells

${ }^{a}$ Versus untreated EH patients

b Versus EH patients treated with lercanidipine for 1 month 
respectively), although all values fell within the upper quartile of the normal range. Two months of lercanidipine treatment significantly reduced WBC and PMNL counts (Table 2).

\section{Percentage of Apoptotic PMNLs}

The percentage of apoptotic PMNLs, assayed immediately after blood withdrawal in whole blood, was significantly higher in EH group of patients (Fig. 1), as compared to NCs $(2.8 \% \pm 0.7 \%)$. One month of lercanidipine treatment significantly reduced the percentage of apoptotic PMNLs, a reduction that was further amplified after 2 months of treatment.

\section{Systemic Inflammation}

\section{Measurement of Plasma Fibrinogen}

Plasma fibrinogen levels fell within the upper quartile of the normal range and were higher than the levels of the NC subjects ( $289 \pm 12 \mathrm{mg}$ / dL). A slight nonsignificant reduction in plasma

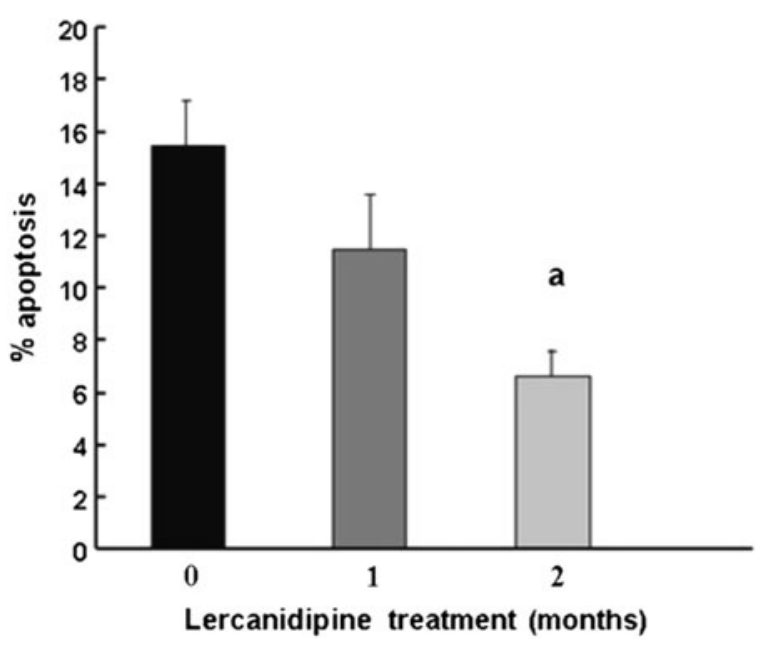

Fig. 1 PMNL apoptosis in whole blood of EH patients before and following 1 and 2 months of lercanidipine treatment. Data are mean \pm SEM. ${ }^{a} P=0.001$ versus PMNLs from untreated $E H$ patients. $E H$ essential hypertension, PMNL peripheral polymorphonuclear leukocytes fibrinogen levels was found after 2 months of lercanidipine treatment (Table 2).

\section{Measurement of CRP, Albumin, and Transferrin}

Significantly decreased serum CRP levels were shown after 2 months of lercanidipine treatment compared with untreated EH $(1.46 \pm 0.1 \mathrm{mg} / \mathrm{L} ; \quad$ Fig. 2$)$. Increased serum albumin levels were found in NCs and treated $\mathrm{EH}$ patients compared with untreated $\mathrm{EH}$ patients, although all fell within normal range. In addition, a significant change was found in the serum transferrin levels of NCs compared with untreated EH (Table 2).

\section{Insulin as a Marker of Insulin Resistance}

Fasting serum insulin levels served as a measure of insulin resistance [9]. Figure 3 shows a significant decrease of serum insulin levels after 2 months of lercanidipine treatment, although levels were still higher than levels in NCs $(8.4 \pm 0.9 \mu \mathrm{U} / \mathrm{mL})$ after 2 months of treatment. It has to be emphasized that in these mild-to-moderate untreated $\mathrm{EH}$ patients,

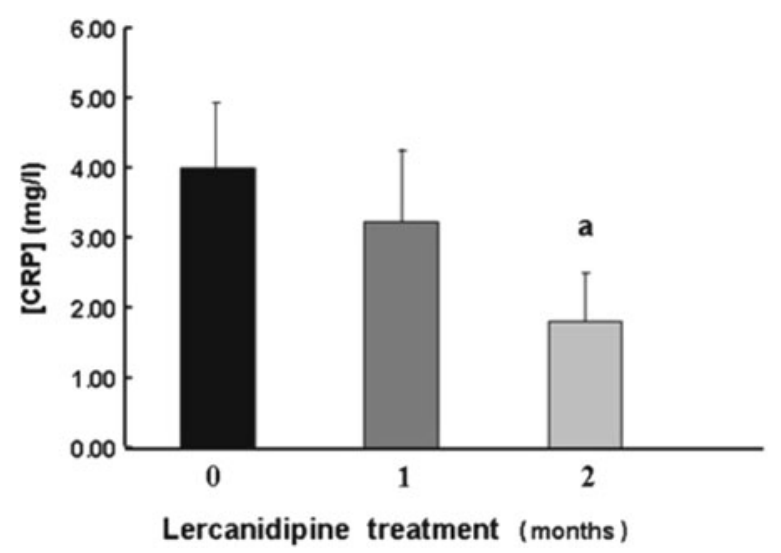

Fig. 2 Serum CRP levels in EH patients before and following 1 and 2 months of lercanidipine treatment. Data are mean \pm SEM. ${ }^{a} P=0.001$ versus sera from untreated $\mathrm{EH}$ patients. CRP C-reactive protein, $E H$ essential hypertension 


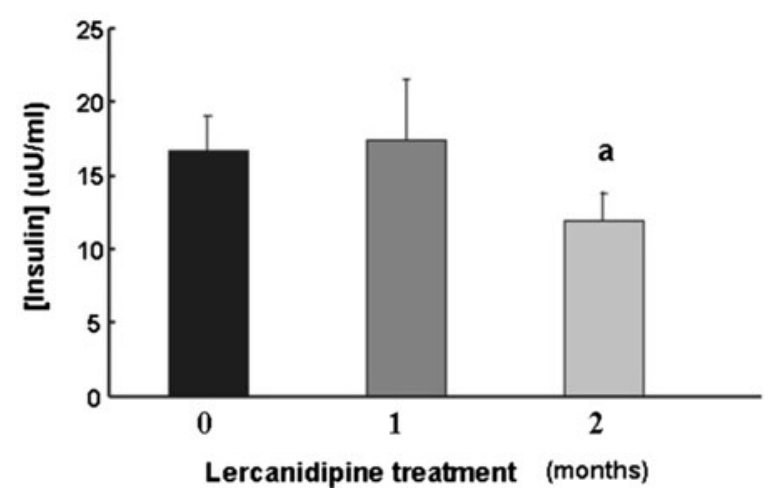

Fig. 3 Serum insulin levels in EH patients before and following 1 and 2 months of lercanidipine treatment. Data are mean \pm SEM. ${ }^{a} P=0.004$ versus sera from untreated $\mathrm{EH}$ patients. $E H$ essential hypertension

most serum insulin levels were within the normal range, although in the upper quartile.

\section{PMNL Priming and Inflammation} in Relation to MAP

PMNL priming expressed by the rate of superoxide release in NCs and $\mathrm{EH}$ patients (treated and untreated with lercanidipine) was positively correlated with MAP: $r=0.43$, $P<0.001 \quad(n=106 ; \quad$ Fig. $4 a)$; the higher the blood pressure parameter, the higher the superoxide release. The WBC counts from NCs and $\mathrm{EH}$ patients (treated and untreated with lercanidipine) were positively correlated with MAP: $r=0.25, P=0.009$ ( $n=109$; Fig. $4 b$ ). The peripheral PMNL counts from NCs and $\mathrm{EH}$ patients (treated and untreated with lercanidipine) were also positively correlated with MAP: $r=0.2, P=0.04(n=109$; Fig. $4 c)$.

\section{Systemic Inflammation Parameters}

\section{in Relation to MAP}

Fibrinogen and CRP, the accepted positive systemic inflammation markers, determined in NCs and EH patients (treated and untreated with lercanidipine), correlated with MAP.
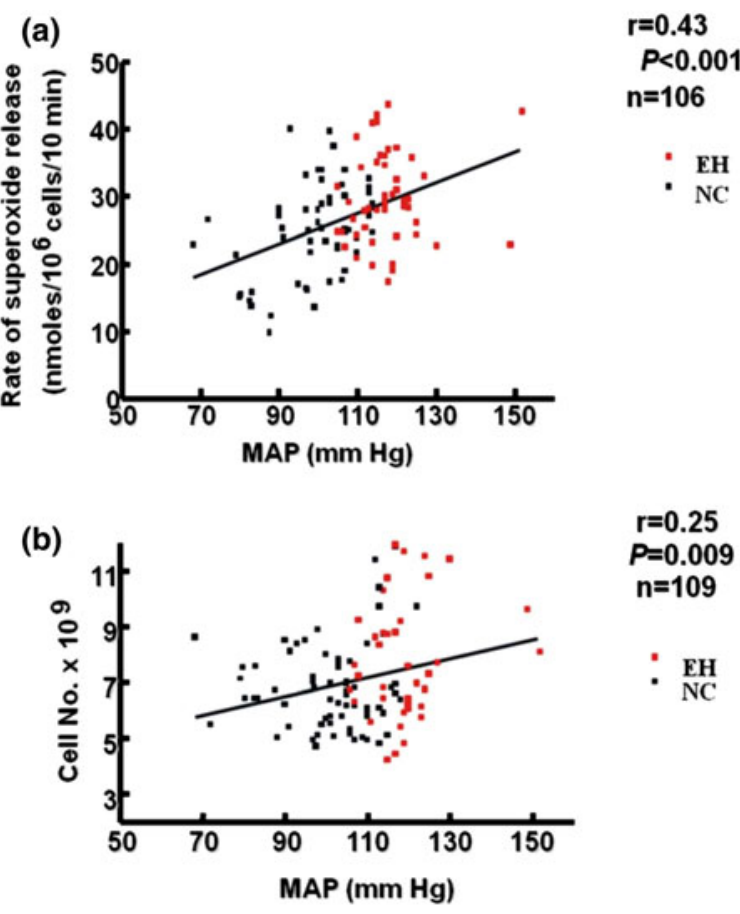

$r=0.25$

$P=0.009$

$n=109$

$: \underset{\mathrm{NC}}{\mathrm{EH}}$

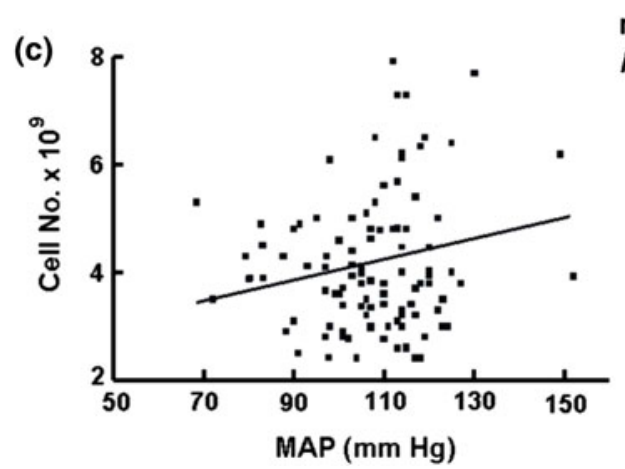

$\mathrm{r}=0.2$

$P=0.04$

Fig. 4 Correlation between the rates of superoxide release from separated PMA-stimulated PMNLs and MAP (a); correlation between WBC counts and MAP (b); correlation between PMNL counts and MAP (c). Data refer to values from all $\mathrm{EH}$ patients (treated and untreated) and NC subjects $(\mathbf{a} ; n=106, \mathbf{b}$ and $\mathbf{c} ; n=109) . E H$ essential hypertension, $M A P$ mean arterial pressure, $N C$ normal control, $P M A$ phorbol 12-myristate 13-acetate, $P M N L$ peripheral polymorphonuclear leukocytes, $W B C$ white blood cells

Plasma fibrinogen levels positively correlated with MAP: $r=0.27, P=0.007$ ( $n=101$; Fig. 5a). However, no correlation could be found between serum CRP levels and MAP: $r=0.05$, $P=0.6$ ( $n=109$; Fig. 5b). 

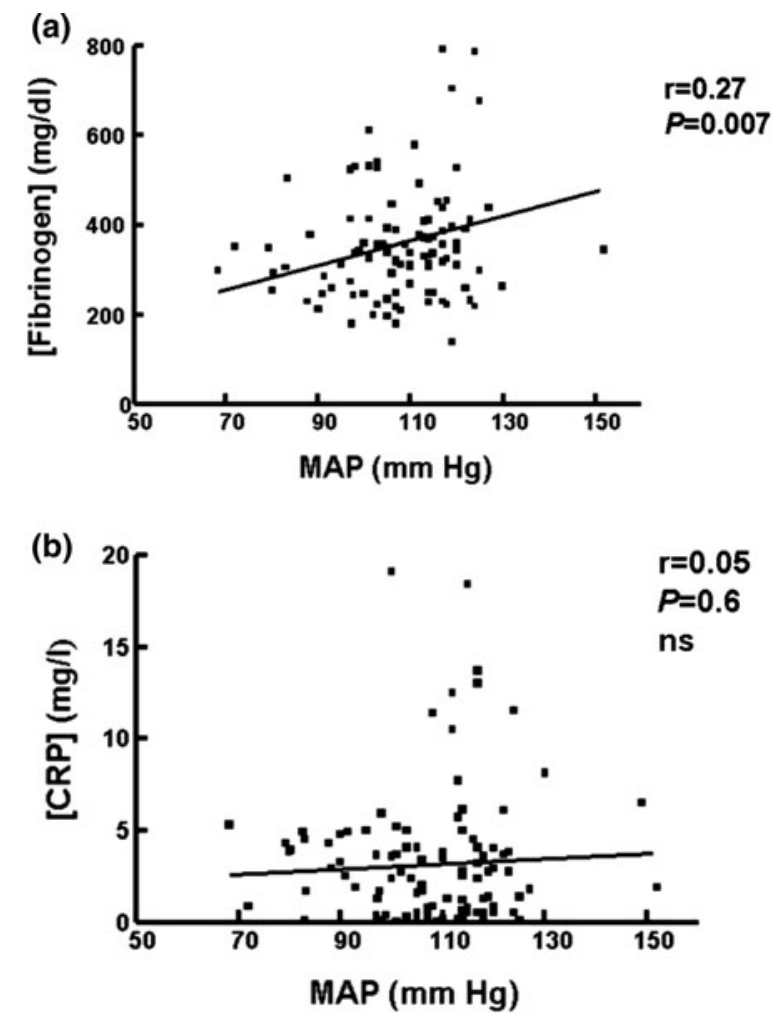

Fig. 5 Correlation between plasma fibrinogen levels and MAP (a); correlation between serum CRP levels and MAP (b). Data refer to values from all EH patients (treated and untreated) and NC subjects. (a; $n=101, \mathbf{b} ; n=109)$. $C R P$ C-reactive patients, $E H$ essential hypertension, $M A P$ mean arterial pressure, $N C$ normal control

\section{Serum Insulin Levels in Relation to MAP}

Fasting serum insulin levels, serving as a measure for insulin resistance, positively correlated with MAP: $r=0.36, \quad P=0.0001$ ( $n=110$; Fig. 6).

\section{DISCUSSION}

The present study evaluates the role of lercanidipine, a dihydropyridine $\mathrm{CCB}$, in mildto-moderate hypertensive patients and its nontraditional effects on PMNL priming, PMNL-related inflammation, systemic inflammation markers, and insulin resistance.

The authors' previous studies showed that $\mathrm{EH}$ is accompanied by a primed state of PMNLs,

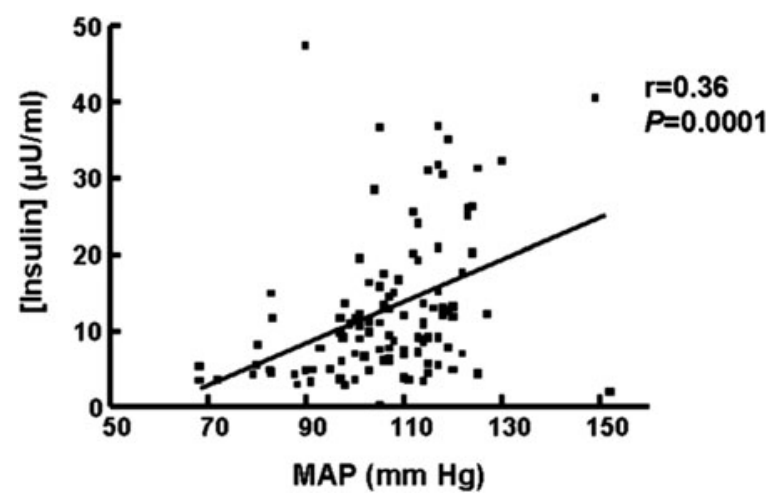

Fig. 6 Correlation between serum insulin levels and MAP. Data refer to values from all $\mathrm{EH}$ patients (treated and untreated) and NC subjects $(n=110)$. EH essential hypertension, $M A P$ mean arterial pressure, $N C$ normal control

inducing OS and inflammation [8, 9]. The authors have defined PMNL priming as a common denominator in other clinical states, such as hypertension, diabetes, and in cigarette smoking, which is known to be associated with endothelial dysfunction, accelerated atherosclerosis, and increased prevalence of cardiovascular morbidity and mortality $[8,9$, $11,12]$. In addition, the authors have recently shown that PMNL priming constitutes a key mediator of low-grade inflammation and OS associated with renal failure [10]. In the present study, the authors examined the PMNL-related priming and inflammation parameters from $\mathrm{EH}$ patients before and after 1 and 2 months of antihypertensive treatment.

A novel, interesting observation was the significantly higher percentage of apoptotic PMNL in EH patients as compared to NC, and the significant decrease in the percentage of apoptotic PMNLs after only 1 month of treatment with lercanidipine; a reduction further amplified after 2 months of treatment. PMNL apoptosis has already been shown to be associated with low-grade inflammation parameters, along with WBC and PMNL counts 
[10], which constitute a mortality predictor in hemodialysis patients [22, 23], and as a predictor for developing chronic kidney disease [24]. In the present study, WBC and PMNL counts were also higher in $\mathrm{EH}$ patients, and declined significantly after treatment with lercanidipine, exhibiting a reduction in the PMNL-related lowgrade inflammation.

In parallel, other systemic inflammation markers, such as CRP, fibrinogen, transferrin, and albumin were also assessed. Serum albumin is a negative acute-phase protein whose low level is attributed to inflammation [25]; although in the normal range, the authors showed a significant increase following lercanidipine treatment. Th reduction in fibrinogen was slight and nonsignificant, and transferrin levels did not change, possibly due to the relatively small number of the patients. An interesting observation from the present study is the significant decrease in CRP level during treatment with lercanidipine to low levels as observed in $\mathrm{NC}$, which are predictive of reduced cardiovascular risk. Numerous studies have demonstrated that elevated CRP levels and upper quartile of normal levels are highly predictive of an increased incidence of cardiovascular events in healthy males and females [26-28]. The low-grade inflammation derived from PMNL priming does not correlate with CRP. These findings imply that different processes are involved in inflammation, which need to be further clarified.

In the present study, lercanidipine treatment significantly lowered fasting serum insulin levels. EH patients have higher plasma insulin levels in response to glucose load, whether obese or of normal body weight [29]. This hyperinsulinemia is a consequence of resistance to the effects of insulin on peripheral glucose utilization and to decreased hepatic uptake of insulin [30]. Elevated $\left[\mathrm{Ca}^{2+}\right]_{\mathrm{i}}$ has been described in various cells in insulinresistant states, such as uremia, diabetes, and EH [31-33]. The present authors have previously showed a link between PMNL $\left[\mathrm{Ca}^{2+}\right]_{i}$, plasma insulin in $\mathrm{EH}$, and elevated $\left[\mathrm{Ca}^{2+}\right]_{\mathrm{i}}$, contributing to OS and inflammation [9]. Furthermore, the reported correlation of individual blood pressure with both PMNL $\left[\mathrm{Ca}^{2+}\right]_{\mathrm{i}}$ and plasma insulin levels, together with the fact that elevated PMNL $\left[\mathrm{Ca}^{2+}\right]_{\mathrm{i}}$ mediates PMNL priming, suggest that elevated PMNL $\left[\mathrm{Ca}^{2+}\right]_{\mathrm{i}}$ and insulin are involved in the pathogenesis of hypertension-induced vascular injury in $\mathrm{EH}$. The cause of slight increases in glucose levels of the normal upper limit after 2 months' treatment is not exactly known, but could be related to high activity of the enzyme hormone-sensitive lipase due to low concentrations of insulin [34]. However, follow-up after several months showed that diabetes or prediabetes did not develop in any of the participant patients.

In the present study, the authors showed a correlation between MAP and PMNL-related priming, and inflammation parameters. A significant link between blood pressure and ROS formation by PMNLs has been observed by Yasunari et al. [35]. In addition, Yasunari et al. reported inhibition of ROS formation by PMNLs after treatment with benidipine, a longacting CCB, which can be attributed in part to the decreased blood pressure. However, Yasunari et al. [35] did not completely rule out the possibility that the drug itself served as an antioxidative agent. In the present study, lercanidipine, a long-acting $\mathrm{CCB}$, was chosen for treating hypertension because it shows high efficacy in mild-to-moderate hypertension and has a low incidence of adverse effects and good tolerability by most patients. Several studies have demonstrated that lercanidipine shows anti-ischemic and antioxidative effects [18, 
36-39] due to its ability to inhibit the growth of smooth muscle cells and their migration to the blood vessel wall, indicating a possible antiatherosclerotic effect of the drug [37, 40]; thus, may be useful in the treatment of insulinresistant hypertensive patients.

The small sample size was not randomized or blinded, as the authors had to select appropriate patients based on the inclusion criteria (no smoking and no other chronic illness, and without any hypertensive treatment that may cause a change in inflammatory markers). However, it was not simple to find patients who meet these inclusion criteria. Other limitations include the control group, who were also the untreated $\mathrm{EH}$ patients at baseline. Furthermore, the examined drug has not yet been tested in vitro; it has only been tested in small sample studies whose positive results have not yet been published.

In summary, lercanidipine, in addition to its effect as an antihypertensive drug, carries antiinflammatory features improving most inflammation markers, systemic and PMNLrelated, and can improve insulin sensitivity. The amelioration in the inflammatory parameters can be attributed, in part, to the decrease in blood pressure. Future, in vitro experiments are needed to find a direct effect of lercanidipine on PMNL-contributed lowgrade inflammation.

\section{ACKNOWLEDGMENTS}

This work was partially supported by Dexon Ltd. Dr. Farah is the guarantor for this article and takes responsibility for the integrity of the work as a whole.

Conflict of interest. The authors declare no conflict of interests.
Open Access. This article is distributed under the terms of the Creative Commons Attribution Noncommercial License which permits any noncommercial use, distribution, and reproduction in any medium, provided the original author(s) and the source are credited.

\section{REFERENCES}

1. Burt VL, Cutler JA, Higgins M, et al. Trends in the prevalence, awareness, treatment, and control of hypertension in the adult US population. Data from the health examination surveys, 1960 to 1991. Hypertension. 1995;26:60-9.

2. Mosterd A, D'Agostino RB, Silbershatz $\mathrm{H}$, et al. Trends in the prevalence of hypertension, antihypertensive therapy, and left ventricular hypertrophy from 1950 to 1989. N Engl J Med. 1999;340:1221-7.

3. Swislocki ALM, Hoffman BB, Reaven GM. Insulin resistance, glucose intolerance and hyperinsulinemia in patients with hypertension. Am J Hypertens. 1989;2:419-23.

4. The 1993 Guidelines for the management of mild hypertension: memorandum from a WHO/ISH meeting. Bull World Health Organ. 1993;71: 503-17.

5. Alexander RW. Hypertension and the pathogenesis of atherosclerosis. Oxidative stress and the mediation of arterial inflammatory response: a new perspective. Hypertension. 1995;25:155-61.

6. Smedly LA, Tonnesen MG, Sandhaus RA, et al. Neutrophil-mediated injury to endothelial cells. J Clin Invest. 1986;77:1233-43.

7. Weiss SJ. Tissue destruction by neutrophils. N Engl J Med. 1989;320:365-76.

8. Kristal B, Shurtz-Swirski R, Chezar J, et al. Participation of peripheral polymorphonuclear leukocytes in the oxidative stress and inflammation in patients with essential hypertension. Am J Hypertens. 1998;11:921-8.

9. Sela S, Shurtz-Swirski R, Farah R, et al. A link between polymorphonuclear leukocyte intracellular calcium, plasma insulin, and essential hypertension. Am J Hypertens. 2002;15:291-5.

10. Sela S, Shurtz-Swirski R, Cohen-Mazor M, et al. The primed peripheral polymorphonuclear leukocyte: a 
culprit underlying chronic low-grade inflammation and systemic oxidative stress in chronic kidney disease. J Am Soc Nephrol. 2005;16:2431-8.

11. Shurtz-Swirski R, Sela S, Herskovits AT, et al. Involvement of polymorphonuclear leukocytes in oxidative stress and inflammation in type 2 diabetes. Diabetes Care. 2001;24:104-10.

12. Sela S, Shurtz-Swirski R, Awad J, et al. The involvement of peripheral polymorphonuclear leukocytes in oxidative stress and inflammation in cigarette smokers. Isr Med Assoc J. 2002;4:1015-9.

13. Tulenko TN, Sumner AE, Chen M, Huang Y, LauryKleintop L, Ferdinand FD. The smooth muscle cell membrane during atherogenesis: a potential target for amlodipine in atheroprotection. Am Heart J. 2001;141(Suppl 2):S1-11.

14. Pitt B, Byington RP, Furberg CD, et al. Effect of amlodipine on the progression of atherosclerosis and the occurrence of clinical events. PREVENT Investigators. Circulation. 2000;102:1503-10.

15. Hernandez RH, Armas-Hernandez MJ, Velasco M, Israili ZH, Armas-Padilla MC. Calcium antagonists and atherosclerosis protection in hypertension. Am J Ther. 2003;10:409-14.

16. Napoli C, Salomone S, Godfraind T, et al. 1,4Dihydropyridine calcium channel blockers inhibit plasma and LDL oxidation and formation of oxidation-specific epitopes in the arterial wall and prolong survival in stroke-prone spontaneously hypertensive rats. Stroke. 1999;30:1907-15.

17. Toyo-oka T, Nayler WG. Third generation calcium entry blockers. Blood Press. 1996;5:206-8.

18. Bang LM, Chapman TM, Goa KL. Lercanidipine. A review of its efficacy in the management of hypertension. Drugs. 2003;63:2449-72.

19. Klebanoff SJ, Clark RA. Iodination by human polymorphonuclear leukocytes: a re-evaluation. J Lab Clin Med. 1977;89:675-86.

20. Babior BM, Kipnes RS, Curnutte JJ. Biological defense mechanisms. The production by leukocytes of superoxide, a potential bactericidal agent. J Clin Invest. 1973;52:741-4.

21. Kuypers FA, Lewis RA, Hua M, et al. Detection of altered membrane phospholipid asymmetry in subpopulations of human red blood cells using fluorescently labeled annexin V. Blood. 1996;87:1179-87.

22. Reddan DN, Klassen PS, Szczech LA, et al. White blood cells as a novel mortality predictor in haemodialysis patients. Nephrol Dial Transplant. 2003;18:1167-73.

23. Pifer TB, McCullough KP, Port FK, et al. Mortality risk in hemodialysis patients and changes in nutritional indicators: DOPPS. Kidney Int. 2002;62:2238-45.

24. Erlinger TP, Tarver-Carr ME, Powe NR, et al. Leukocytosis, hypoalbuminemia, and the risk for chronic kidney disease in US adults. Am J Kidney Dis. 2003;42:256-63.

25. Tsirpanlis G, Bagos P, Ioannou D, et al. Serum albumin: a late-reacting negative acute-phase protein in clinically evident inflammation in dialysis patients. Nephrol Dial Transplant. 2005;20:658-9.

26. Ridker PM, Rifai N, Clearfield M, et al. Air Force/ Texas Coronary Atherosclerosis Prevention Study Investigators. Measurement of C-reactive protein for the targeting of statin therapy in the primary prevention of acute coronary events. N Engl J Med. 2001;344:1959-65.

27. Koenig W, Sund M, Frohlich M, et al. C-reactive protein, a sensitive marker of inflammation, predicts future risk of coronary heart disease in initially healthy middle-aged men: results from the MONICA (Monitoring Trends and Determinants in Cardiovascular Disease) Augsburg Cohort Study, 1984 to 1992. Circulation. 1999;99:237-42.

28. Kuller LH, Tracy RP, Shaten J, Meilahn EN. Relation of C-reactive protein and coronary heart disease in the MRFIT nested case-control study. Multiple Risk Factor Intervention Trial. Am J Epidemiol. 1996;144:537-47.

29. De Fronzo RA, Ferrannini E. Insulin resistance. A multifaceted syndrome responsible for NIDDM, obesity, hypertension, dyslipidemia and atherosclerotic cardiovascular disease. Diabetes Care. 1991;14:173-94.

30. Reaven GM, Laws A. Insulin resistance, compensatory hyperinsulenemia, and coronary heart disease. Diabetology. 1994;37:948-52.

31. Ohno Y, Matsuo K, Suzuki H, et al. Genotypes of sarco (endo) plasmic reticulum $\mathrm{Ca}++$-dependent ATPase II gene in substrains of spontaneously hypertensive rats. J Hypertens. 1996;14:271-87.

32. Ware JA, Clark AB, Smith M, Salzman EW. Abnormalities of cytoplasmic $\mathrm{Ca}^{2+}$ in platelets from patients with uremia. Blood. 1989;73:172-6.

33. Draznin B. Cytosolic calcium and insulin resistance. Am J Kidney Dis. 1993;21:32-8. 
34. Claus TH, Lowe DB, Liang Y, et al. Specific inhibition of hormone-sensitive lipase improves lipid profile while reducing plasma glucose. J Pharmacol Exp Ther. 2005;315:1396-402.

35. Yasunari K, Maeda K, Nakamura M, Watanabe T, Yoshikawa J. Benidipine, a long-acting calcium channel blocker, inhibits oxidative stress in polymorphonuclear cells in patients with essential hypertension. Hypertens Res. 2005;28:107-12.

36. Tomlinson B, Benzie IF. Antioxidant effect of lercanidipine. Hypertension. 2003;42:10-1.

37. Bellosta S, Bernini F. Lipophilic calcium antagonists in antiatherosclerotic therapy. Curr Atheroscler Rep. 2000;2:76-81.
38. Farah R, Shurtz-Swirski R. The combined effect of calcium channel blocker lercanidipine and antioxidants on low-grade systemic inflammation parameters in essential hypertension patients. Minerva Cardioangiol. 2008;56:467-76.

39. Martinez ML, Rizzi E, Castro MM, et al. Lercanidipine decreases vascular matrix metalloproteinase-2 activity and protects against vascular dysfunction in diabetic rats. Eur J Pharmacol. 2008;599:110-6.

40. Wu JR, Liou SF, Lin SW, et al. Lercanidipine inhibits vascular smooth muscle cell proliferation and neointimal formation via reducing intracellular reactive oxygen species and inactivating RasERK1/2 signaling. Pharmacol Res. 2009;59:48-56. 